\title{
Efficient Depletion of Fission Yeast Condensin by Combined Transcriptional Repression and Auxin-Induced Degradation
}

\section{Yasutaka Kakui and Frank UhImann}

\begin{abstract}
Structural maintenance of chromosomes (SMC) complexes play pivotal roles in controlling chromatin organization. Condensin is an essential SMC complex that compacts chromatin to form condensed chromosomes in mitosis. Complete condensin inactivation is necessary to reveal how condensin converts interphase chromatin into mitotic chromosomes. Here, we have developed a condensin depletion system in fission yeast that combines transcriptional repression with auxin-inducible protein degradation. This achieves efficient condensin depletion without need for a temperature shift. Our system is useful when studying how condensin contributes to chromosome architecture and is applicable to the study of other SMC complexes.
\end{abstract}

Key words Condensin, SMC complex, Chromosome condensation, Auxin-inducible degron, Transcriptional repression, Fission yeast

\section{Introduction}

Spatial chromatin organization by SMC complexes is at the heart of genome stability and faithful chromosome segregation. SMC complexes are evolutionary conserved, large proteinaceous rings that topologically entrap one or more DNAs to engage in higher order chromatin architecture [1]. The SMC family member, condensin, plays a crucial role in the compaction of interphase chromatin to form condensed chromosomes in mitosis [2]. It also plays roles in genome maintenance during interphase. Condensin consists of two SMC coiled-coil subunits, SMC2/Cut14 and SMC4/Cut3, and three non-SMC accessory subunits, CAP-D2/Cndl, CAP-H/ $\mathrm{Cnd} 2$, and CAP-G/Cnd3 (Fig. la). How condensin accomplishes chromosome condensation is not yet understood.

To study condensin's function in vivo, an important approach is to inactivate or deplete the complex. Historically, temperature sensitive mutants obtained in yeast genetic screens have been utilized to characterize protein function. In fission yeast, condensin 
a

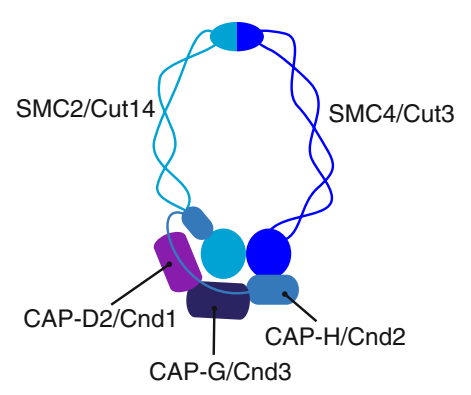

b

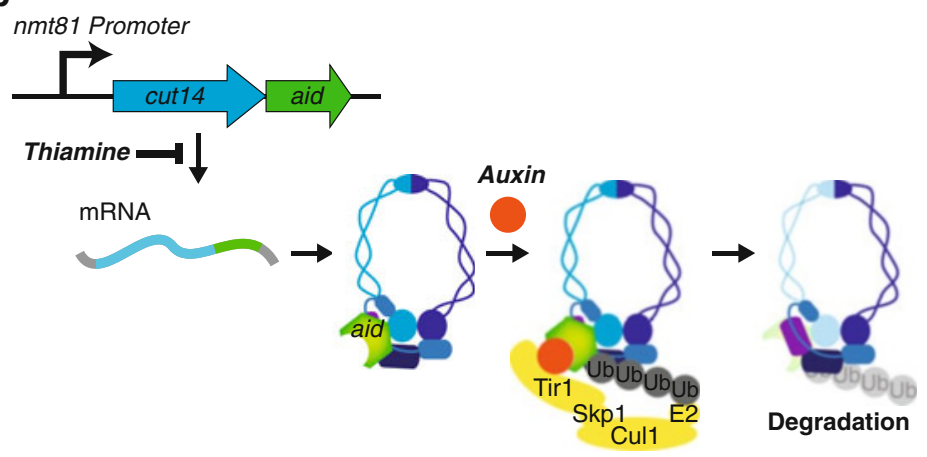

Fig. 1 Schematic illustration of the cut14 shut off system. (a) A schematic of condensin. (b) Condensin depletion strategy. The endogenous promoter of the cut14 gene is replaced by weakened version of thiamine repressible $n m t 1$ promoter, nmt81. The cut14 gene is also fused to an auxin-inducible degron (aid) tag. Addition of thiamine to the growth medium represses cut14 transcription. Auxin addition targets Cut14 for degradation through ubiquitination by the SCF (Cul1-Skp1-Tir1) complex

temperature sensitive mutants have been isolated with a "cell untimely torn (cut)" phenotype [3]. A block to nuclear division, but not cytokinesis, results in chromosomes that are apparently "cut" during cell division. Cytological analyses of these mutants have revealed the importance of condensin for mitotic chromosome condensation [4]. These temperature-sensitive mutants provide a powerful tool but also come with limitations. It is difficult to know how quickly and how completely condensin is inactivated after temperature shift. Furthermore, the required temperature shift not only inactivates condensin but affects cell physiology in additional ways (e.g., eliciting a transcriptional heat shock response) that could impact on chromatin architecture.

Alternatives to temperature sensitive mutants have been developed. Protein function can be eliminated by forced localization away from its required site of action. In case of budding yeast condensin, cytoplasmic sequestration using the anchor-away approach successfully abolishes nuclear condensin function [5-7]. However rapamycin, the ligand used to sequester condensin to its cytoplasmic anchor, inhibits cell growth. Elaborate strain construction is required to circumvent this effect.

Condensin depletion in vertebrates has been achieved using RNA interference or promoter shut-off [8-10]. In these cases, depletion progresses slowly, typically over the duration of several cell divisions. Consequently, condensin depletion at the time of analysis is often incomplete. An alternative approach is the use of TEV protease to target and inactivate an engineered condensin complex more quickly [11]. Recently, efficient depletion of chicken DT40 cell condensin was reported using an auxin-inducible degron (aid) [12]. 
In fission yeast, the thiamine repressible nmtl promoter and derivatives have been used to repress gene transcription $[13,14]$. Replacing endogenous gene promoters with the nmt1 promoter has allowed for efficient depletion of proteins that are intrinsically unstable, such as the APC/C activator Slpl or DNA replication licensing factor Cdc18 [15, 16]. Condensin depletion under control of the $n m t 1$ promoter has been reported, but depletion remains incomplete even after longer periods [17]. Following transcriptional repression, protein degradation depends on physiological protein turnover. The stability of condensin prevents its acute depletion by transcriptional repression alone.

We therefore decided to combine transcriptional repression with conditional destabilization of condensin using an auxininducible degron. The aid approach relies on the SCF (Skp, Cullin, F-box containing complex)-proteasome pathway to degrade a target protein $[18,19]$. The plant-specific F-box protein Tirl recognizes an aid degron tag, fused to condensin, only in the presence of the plant hormone auxin (Fig. Ib). Together with transcriptional repression this leads to improved condensin depletion.

Here we document this condensin depletion protocol in fission yeast. We target the SMC2/Cutl4 subunit for depletion, one of the two central coiled-coil subunits that are crucial for condensin complex assembly (Fig. la). The endogenous cutl4 promoter is replaced by the weaker $n m t 1$ promoter, $n m t 81$, and an aid tag is fused to the C-terminus of Cutl4. Two copies of Tirl, derived from two plant species, are expressed for efficient targeting [19]. Addition of thiamine to represses cut14 expression and auxin to destabilize the Cutl 4 protein together lead to fast and efficient condensin depletion (see Fig. 3, below). This approach facilitated the study of condensin's contribution to chromosome formation in fission yeast [20] and should be applicable to the study of other SMC complex members.

\section{Materials}

\subsection{Cell Culture}

1. Pombe Glutamate medium (PMG): $14.7 \mathrm{mM}$ potassium hydrogen phthalate, $15.5 \mathrm{mM} \mathrm{Na} \mathrm{HPO}_{4}, 3.75 \mathrm{~g} / \mathrm{L}$ L-glutamic acid, monosodium salt, $2 \%(\mathrm{w} / \mathrm{v})$ glucose, $5.2 \mathrm{mM} \mathrm{MgCl}_{2}$, $0.1 \mathrm{mM} \mathrm{CaCl}_{2}, 13.4 \mathrm{mM} \mathrm{KCl}, 0.28 \mathrm{mM} \mathrm{Na}_{2} \mathrm{SO}_{4}, 4.2 \mu \mathrm{M}$ pantothenic acid, 81.2 $\mu \mathrm{M}$ nicotinic acid, 55.5 $\mu \mathrm{M}$ inositol, $40.8 \mathrm{nM}$ biotin, $8.09 \mu \mathrm{M}$ boric acid, $2.37 \mu \mathrm{M} \mathrm{MnSO}_{4}$, $1.39 \mu \mathrm{M} \mathrm{ZnSO}_{4}, 0.74 \mu \mathrm{M} \mathrm{FeCl}_{2}, 0.247 \mu \mathrm{M}$ molybdic acid, $0.6 \mu \mathrm{M} \mathrm{KI}, 0.16 \mu \mathrm{M} \mathrm{CuSO}_{4}, 4.76 \mu \mathrm{M}$ citric acid. $150 \mu \mathrm{g} / \mathrm{mL}$ adenine, leucine, uracil, lysine, and histidine are added where necessary. 


\section{Table 1}

Yeast strains used in this study

\begin{tabular}{|c|c|}
\hline Strain name & Genotype \\
\hline YUK377 & 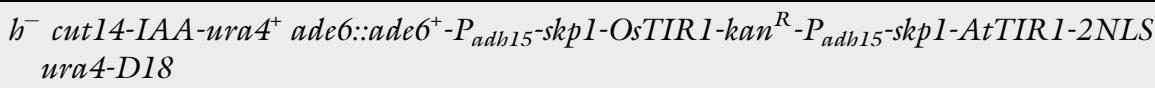 \\
\hline YUK402 & 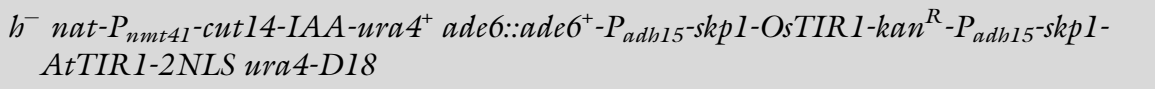 \\
\hline YUK404 & 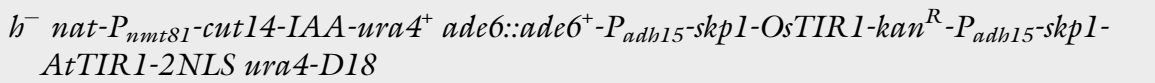 \\
\hline
\end{tabular}

\subsection{Reagents for Western Blotting}

2. $10 \mathrm{mg} / \mathrm{mL}$ thiamine solution: $10 \mathrm{mg} / \mathrm{mL}(\mathrm{w} / \mathrm{v})$ thiamine in deionized water, filter-sterilized.

3. 0.5 M 3-indoleacetic acid (IAA): dissolved in methanol. Prepare this freshly.

4. Yeast strains used in this protocol are listed in Table 1. Two copies of Skpl-Tirl fusion proteins are expressed in all cells for efficient condensin destabilization ( see Note $\mathbf{1}$ ).

1. $0.2 \mathrm{~mL}$ PCR tube.

2. $1.5 \mathrm{~mL}$ tubes.

3. Screw cap $2 \mathrm{~mL}$ tubes.

4. $15 \mathrm{~mL}$ tubes.

5. $50 \mathrm{~mL}$ tubes.

6. Acid-washed glass beads $(425-600 \mu \mathrm{m})$.

7. Needles $\left(23 \mathrm{G} \times \mathrm{l}^{\prime \prime}\right)$.

8. $20 \%$ trichloroacetic acid solution (TCA).

9. $1 \mathrm{M}$ Tris. No need to adjust $\mathrm{pH}$.

10. $1 \mathrm{M}$ dithiothreitol (DTT): store at $-20^{\circ} \mathrm{C}$.

11. SDS buffer: $100 \mathrm{mM}$ Tris- $\mathrm{HCl}(\mathrm{pH} 6.8), 4 \%(\mathrm{w} / \mathrm{v})$ sodium dodecyl sulfate, $0.2 \%(\mathrm{w} / \mathrm{v})$ bromophenol blue, $20 \%(\mathrm{v} / \mathrm{v})$ glycerol, $200 \mathrm{mM}$ DTT (see Note 2).

12. Nitrocellulose membrane.

13. PBST: $137 \mathrm{mM} \mathrm{NaCl}, 2.7 \mathrm{mM} \mathrm{KCl}, 10 \mathrm{mM} \mathrm{Na} \mathrm{HPO}_{4}$, $1.8 \mathrm{mM} \mathrm{KH}_{2} \mathrm{PO}_{4}, 1 \%(\mathrm{v} / \mathrm{v})$ Tween 20.

14. Primary antibodies (see Notes 3 and 4 ).

15. Secondary antibody: HRP conjugated anti-mouse antibody.

16. Enhanced chemiluminescent (ECL) detection reagents. 
3 Methods

3.1 Depletion

of the Condensin

SMC2/Cut14 Subunit

3.2 Confirmation of Condensin Depletion by Western Blotting
1. Culture cells in PGM at $25^{\circ} \mathrm{C}$ until $\mathrm{OD}_{595}$ reaches $0.2-0.4$ (4-8 $\times 10^{6}$ cells $\left./ \mathrm{mL}\right)($ see Note 5$)$.

2. Add $1 / 2000$ culture volume of thiamine solution (see Note 6 ).

3. Add $1 / 1000$ culture volume IAA stock solution to the culture ( see Notes 7 and 8 ).

4. Incubate for $3 \mathrm{~h}$ at $25^{\circ} \mathrm{C}$.

5. Collect cells.

1. Harvest $2.5 \mathrm{OD}_{595}$ units of cells $\left(5 \times 10^{7}\right.$ cells $)$ in $15 \mathrm{~mL}$ tubes.

2. Centrifuge at $3000 \mathrm{rpm}$ for $5 \mathrm{~min}$ at $4^{\circ} \mathrm{C}$.

3. Discard the supernatant.

4. Suspend cells in $1 \mathrm{~mL}$ of $20 \%$ TCA solution.

5. Transfer cells to screw cap $2 \mathrm{~mL}$ tube. As required, samples can be stored on ice at this stage.

6. Centrifuge $13,000 \mathrm{rpm}$ for $1 \mathrm{~min}$ at $4{ }^{\circ} \mathrm{C}$.

7. Discard supernatant.

8. Suspend cells in $1 \mathrm{~mL}$ of $1 \mathrm{M}$ Tris.

9. Centrifuge at 13,000 $\mathrm{rpm}$ for $1 \mathrm{~min}$ at $4{ }^{\circ} \mathrm{C}$.

10. Discard supernatant. Remove all the liquid carefully.

11. Suspend cells in $100 \mu \mathrm{L}$ of SDS buffer.

12. Boil at $95^{\circ} \mathrm{C}$ for $2 \mathrm{~min}$.

13. Add $200 \mu \mathrm{L}$ of glass beads to the screw cap $2 \mathrm{~mL}$ tubes (see Note 9).

14. Boil at $95^{\circ} \mathrm{C}$ for $2 \mathrm{~min}$.

15. Break cells using a Multibead shocker $(6.0 \mathrm{~m} / \mathrm{s}$ for $40 \mathrm{~s}$, or until cells are broken).

16. Boil at $95^{\circ} \mathrm{C}$ for $2 \mathrm{~min}$.

17. Puncture the bottom of the screw cap tubes using a $23 \mathrm{G}$ needle ( see Note 10).

18. Place the screw cap tube onto a $1.5 \mathrm{~mL}$ tube (Fig. 2a).

19. Place both tubes into a $50 \mathrm{~mL}$ tube (Fig. 2b).

20. Centrifuge $50 \mathrm{~mL}$ tubes (from step 19) at $1000 \mathrm{rpm}$ for $2 \mathrm{~min}$.

21. Discard screw cap tubes, recover the $1.5 \mathrm{~mL}$ tubes that contain the protein extract ( see Note 11).

22. Boil at $95^{\circ} \mathrm{C}$ for $2 \mathrm{~min}$.

23. Spin at $10,000 \mathrm{rpm}$ at room temperature for $2 \mathrm{~min}$ to remove cell debris. 
a

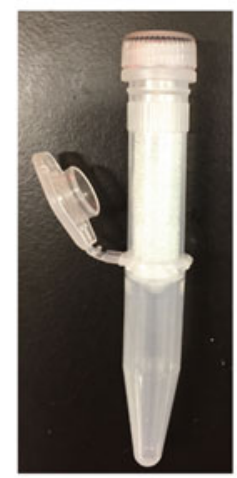

b

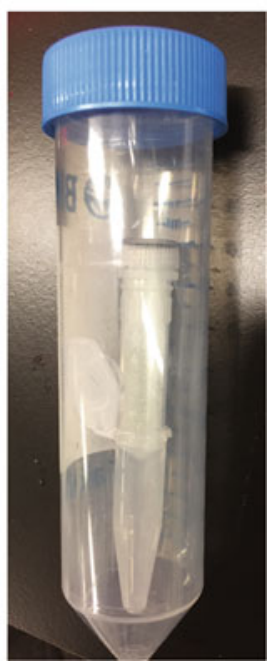

Fig. 2 Setup to recover cell extracts from screw cap tubes after cell breaking. (a) A punctured screw cap tube is firmly placed onto a $1.5 \mathrm{~mL}$ tube. (b) The tubes prepared in (a) are placed into a $50 \mathrm{~mL}$ tube for centrifugation. If handling multiple samples, two sets of tubes can be placed into one $50 \mathrm{~mL}$ tube

24. Load 5-10 $\mu \mathrm{L}$ for analysis by SDS-PAGE.

25. Transfer proteins to a nitrocellulose membrane.

26. Blocking: Incubate the membrane with $5 \%$ skim milk in PBST at room temperature for $30 \mathrm{~min}$.

27. Incubate the membrane with Primary antibody (see Notes 3 and 4 ).

28. Wash the membrane with PBST at room temperature for 5 min.

29. Repeat step $\mathbf{2 8}$ three times.

30. Incubate the membrane with Secondary antibody.

31. Repeat step $\mathbf{2 8}$ three times.

32. Detection of the protein. Follow the manufacturer's instruction for using the ECL reagents.

\section{Notes}

1. Expression levels of the Skpl-Tirl fusion proteins are crucial for efficient target protein degradation [19].

2. Prepare SDS buffer without $200 \mathrm{mM}$ DTT and keep at room temperature. Add $1 / 5$ volume of 1 M DTT to the SDS buffer just before use. 
a

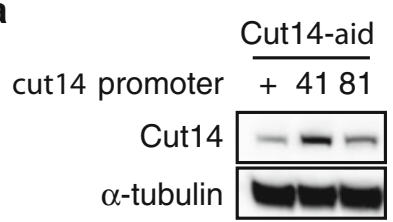

b

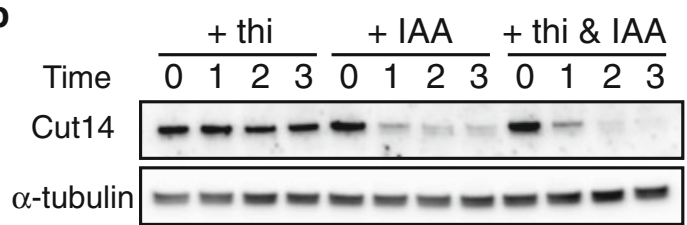

Fig. 3 Cut14 protein levels under the indicated conditions. Protein extracts were prepared as described and analyzed by SDS-PAGE and western blotting. Cut14 and $\alpha$-tubulin were detected using anti-aid tag (IAA17) and anti-TAT1 antibodies, respectively. $\alpha$-tubulin serves as a loading control. (a) Cut14 protein levels expressed from different promoters, in the absence of thiamine. +: endogenous cut14 promoter, 41: nmt41 promoter, 81: nmt81 promoter. The Cut14 expression level under nmt81 promoter control is comparable to endogenous levels. (b) Time course analysis of Cut14 depletion under the indicated conditions. Samples were taken every hour after addition of either thiamine (+thi), IAA (+IAA) or both thiamine and IAA (+thi \& IAA). Time is indicated in hours. Cut14 protein is hardly detectable $2 \mathrm{~h}$ after addition of both thiamine and IAA

3. Anti-aid tag (IAA17) antibody, Cosmobio, CAC-APC004AM. Use at 1:5000 dilution in 5\% skim milk. We found this anti-aid antibody to be weak but specific. Overnight incubation at $4{ }^{\circ} \mathrm{C}$ is recommended.

4. Anti-Tatl antibody: Anti-Tatl antibodies are comparatively strong. Incubation at room temperature for $l \mathrm{~h}$ is recommended.

5. To prepare a culture with suitable density in the next morning, an inoculation at $\mathrm{OD}_{595}=0.05$ (approximately $1 \times 10^{6}$ cells $/$ $\mathrm{mL}$ ) and overnight growth is recommended.

6. When comparing nmtl-derived promoters of different strengths, we found that an attenuated variant, $n m t 81$, yields Cutl4 levels similar to the endogenous cutl4 promoter (Fig. 3a). Addition of thiamine led to only weak depletion of Cutl 4 protein after $3 \mathrm{~h}$ (Fig. 3b).

7. An aid tag fused to Cutl4 destabilizes condensin within $60 \mathrm{~min}$, although Cutl 4 is still detected even after $3 \mathrm{~h}$ if the $n m t 81$ promoter remains active (Fig. 3 b). Simultaneous addition of thiamine and auxin leads to almost complete condensin depletion in less than $2 \mathrm{~h}$ (Fig. 3b).

8. The timing of IAA addition can be adjusted, for example, to accommodate arrest at a certain cell cycle stage. To minimize chromosome segregation defects in mitosis prior to a cell cycle arrest, thiamine and auxin can be added $180 \mathrm{~min}$ and $90 \mathrm{~min}$ before the arrest endpoint, respectively [20].

9. Use a $0.2 \mathrm{~mL}$ PCR tube that can be glued to an inoculation loop as a handle for ease of use. One scoop of glass beads is $200 \mu \mathrm{L}$. 
10. Spin down briefly, then loosen the screw cap to release the pressure and close again tightly to avoid spillage while puncturing the tube.

11. These $50 \mathrm{~mL}$ tubes can be reused.

\section{Acknowledgments}

We would like to thank Prof. Masukata for strains and plasmids. This work was supported by the European Research Council and the Francis Crick Institute, which receives its core funding from Cancer Research UK (FC001198), the UK Medical Research Council (FC001198), and the Wellcome Trust (FC001198). Y.K. was supported by the Japanese Society for the Promotion of Science (JSPS).

\section{References}

1. Uhlmann F (2016) SMC complexes: from DNA to chromosomes. Nat Rev Mol Cell Biol 17:399-412

2. Hirano T (2016) Condensin-based chromosome organization from bacteria to vertebrates. Cell 164:847-857

3. Hirano T, Funahashi S, Uemura T, Yanagida M (1986) Isolation and characterization of Schizosaccharomyces pombe cut mutants that block nuclear division but not cytokinesis. EMBO J 5:2973-2979

4. Saka Y, Sutani T, Yamashita Y, Saitoh S, Takeuchi M, Nakaseko Y, Yanagida M (1994) Fission yeast cut 3 and cut 14 , members of a ubiquitous protein family, are required for chromosome condensation and segregation in mitosis. EMBO J 13:4938-4952

5. Haruki H, Nishikawa J, Laemmli UK (2008) The anchor-away technique: rapid, conditional establishment of yeast mutant phenotypes. Mol Cell 31:925-932

6. Cheng TM, Heeger S, Chaleil RA, Matthews N, Stewart A, Wright J, Lim C, Bates PA, Uhlmann F (2015) A simple biophysical model emulates budding yeast chromosome condensation. Elife 4:e05565

7. Charbin A, Bouchoux C, Uhlmann F (2014) Condensin aids sister chromatid decatenation by topoisomerase II. Nucleic Acids Res 42:340-348

8. Ono T, Losada A, Hirano M, Myers MP, Neuwald AF, Hirano T (2003) Differential contributions of condensin I and condensin II to mitotic chromosome architecture in vertebrate cells. Cell 115:109-121
9. Hirota T, Gerlich D, Koch B, Ellenberg J, Peters JM (2004) Distinct functions of condensin I and II in mitotic chromosome assembly. J Cell Sci 117:6435-6445

10. Hudson DF, Vagnarelli P, Gassmann R, Earnshaw WC (2003) Condensin is required for nonhistone protein assembly and structural integrity of vertebrate mitotic chromosomes. Dev Cell 5:323-336

11. Houlard M, Godwin J, Metson J, Lee J, Hirano T, Nasmyth K (2015) Condensin confers the longitudinal rigidity of chromosomes. Nat Cell Biol 17:771-781

12. Gibcus JH, Samejima K, Goloborodko A, Samejima I, Naumova N, Nuebler J, Kanemaki MT, Xie L, Paulson JR, Earnshaw WC, Mirny LA, Dekker J (2018) A pathway for mitotic chromosome formation. Science 359:6376. pii: eaao6135

13. Maundrell K (1990) nmtl of fission yeast. A highly transcribed gene completely repressed by thiamine. J Biol Chem 265:10857-10864

14. Basi G, Schmid E, Maundrell K (1993) TATA box mutations in the Schizosaccharomyces pombe nmtl promoter affect transcription efficiency but not the transcription start point or thiamine repressibility. Gene 123:131-136

15. Petrova B, Dehler S, Kruitwagen T, Heriche JK, Miura K, Haering CH (2013) Quantitative analysis of chromosome condensation in fission yeast. Mol Cell Biol 33:984-998

16. Hermand D, Nurse P (2007) Cdc18 enforces long-term maintenance of the $S$ phase checkpoint by anchoring the Rad3-Rad26 complex to chromatin. Mol Cell 26:553-563 
17. Sutani T, Sakata T, Nakato R, Masuda $K$, Ishibashi M, Yamashita D, Suzuki Y, Hirano T, Bando M, Shirahige K (2015) Condensin targets and reduces unwound DNA structures associated with transcription in mitotic chromosome condensation. Nat Commun 6:7815

18. Nishimura K, Fukagawa $T$, Takisawa $H$, Kakimoto T, Kanemaki M (2009) An auxinbased degron system for the rapid depletion of proteins in nonplant cells. Nat Methods $6: 917-922$
19. Kanke M, Nishimura K, Kanemaki M, Kakimoto T, Takahashi TS, Nakagawa T, Masukata H (2011) Auxin-inducible protein depletion system in fission yeast. BMC Cell Biol 12:8

20. Kakui Y, Rabinowitz A, Barry DJ, Uhlmann F (2017) Condensin-mediated remodeling of the mitotic chromatin landscape in fission yeast. Nat Genet 49:1553-1557

Open Access This chapter is licensed under the terms of the Creative Commons Attribution 4.0 International License (http://creativecommons.org/licenses/by/4.0/), which permits use, sharing, adaptation, distribution and reproduction in any medium or format, as long as you give appropriate credit to the original author(s) and the source, provide a link to the Creative Commons license and indicate if changes were made.

The images or other third party material in this chapter are included in the chapter's Creative Commons license, unless indicated otherwise in a credit line to the material. If material is not included in the chapter's Creative Commons license and your intended use is not permitted by statutory regulation or exceeds the permitted use, you will need to obtain permission directly from the copyright holder. 